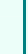

\title{
Fixed Size of Enlarged Calcified Lymph Nodes in Esophageal Adenocarcinoma despite Complete Remission
}

\author{
B.A. Grotenhuis ${ }^{a} \quad$ B.P.L. Wijnhoven ${ }^{a} \quad$ J.J. Hermans ${ }^{b}$ \\ K. Biermann ${ }^{c}$ J.J.B. van Lanschot ${ }^{a}$

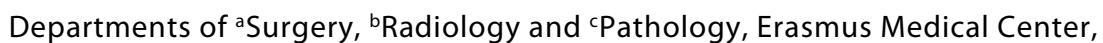 \\ Erasmus University, Rotterdam, The Netherlands
}

\section{Key Words}

Esophageal adenocarcinoma $\cdot$ Calcification $\cdot$ Lymph node $\cdot$ Response evaluation

\begin{abstract}
Untreated malignant lymph nodes that are calcified are rare. Publications on such calcifications are restricted to case reports. We present a case of calcified lymph nodes in a patient with adenocarcinoma of the gastroesophageal junction that seemed to be nonresponsive to induction chemotherapy, as they did not decrease in size. However, on pathological examination of the resected lymph nodes no vital tumor cells could be detected anymore. Therefore, we hypothesize that a calcified lymph node is unable to shrink, even after adequate remission on induction chemotherapy. This should be taken into account when clinical decision-making depends on the change in size of an enlarged, calcified lymph node as a measure of treatment effect.
\end{abstract}

\section{Case Report}

A 59-year-old man presented with progressive dysphagia and weight loss over a period of 6 months. The patient's medical history did not reveal any granulomatous diseases such as sarcoidosis or tuberculosis. On upper gastrointestinal endoscopy, a tumor was detected in the distal esophagus and at the gastroesophageal junction (Siewert type I); biopsies were taken. Histological examination of these biopsies confirmed the presence of an adenocarcinoma. On endoscopic ultrasonography (EUS) a tumor with a length of $8 \mathrm{~cm}$ was seen in the distal esophagus including the gastroesophageal junction. Some locoregional lymph nodes showed a malignant appearance. CT scanning confirmed the presence of the tumor in the distal esophagus and at the gastroesophageal junction (fig. 1a). Furthermore, it was noted on both EUS and CT scanning that remarkably enlarged lymph nodes (20 and $17 \mathrm{~mm}$, respectively) were located near the celiac trunk, which appeared to be calcified (fig. 2a). EUS with fine-needle aspiration of these enlarged nodes was done and cytological examination showed tumor cells (fig. 3 ). Hence, the tumor was classified as CT3N1M1a and was considered ineligible for primary surgical therapy because of the large peritruncal nodes. 
The patient was offered induction chemotherapy to downstage the tumor in order to facilitate radical resection. The patient followed a 6-course weekly treatment with carboplatin/paclitaxel, followed by another 3-weekly treatment with carboplatin/paclitaxel for 3 courses. Response to induction chemotherapy was evaluated at 2 and 5 months after the diagnosis by means of CT scanning. A clear reduction in wall thickness of the primary tumor in the distal esophagus and at the gastroesophageal junction was seen after the patient had completed 9 cycles of chemotherapy (fig. 1b). However, the calcified part of the lymph nodes near the celiac trunk had not decreased in size (fig. 2b). Nevertheless, given the patient's age, good general condition and substantial response of the primary tumor, he was offered surgical resection of the tumor. Six weeks after having finished chemotherapy the patient underwent transhiatal esophagectomy with peritruncal lymph node dissection, followed by gastric tube reconstruction with cervical anastomosis. The calcified lymph nodes could easily be identified intraoperatively and were resected en bloc together with the resection specimen. Postoperative recovery was uneventful, and the patient was discharged home 15 days after the operation. Histological examination of the resection specimen revealed a poorly differentiated adenocarcinoma with tumor-free resection margins (pR0). Furthermore, the primary tumor appeared to contain multiple calcifications. Lymph node metastases were present in 3 locoregional nodes, out of 17 lymph nodes that were resected in total. The enlarged calcified lymph nodes that were located at the celiac trunk did not harbor vital tumor lesions anymore. The tumor was staged as ypT3N1M0.

\section{Discussion}

Calcification of lymph nodes is an abnormal finding on radiological imaging. Calcified lymph nodes mostly involve thoracic and, less frequently, abdominal and pelvic nodes. Nodal calcification is common in benign granulomatous diseases such as sarcoidosis and tuberculosis, in which half of the patients have been reported to have calcification of hilar and/or mediastinal nodes on CT scanning [1]. In hematological malignancies it is well known that lymph nodes may calcify in response to chemo- and/or radiotherapy [2]. Likewise, nodal calcification has been reported in patients with metastatic prostate [3], ovary [4] and colon carcinoma [5] that have been treated with hormonal, chemo- and/or radiotherapy. Moreover, calcification of lymph nodes can be identified by CT scanning as radiation-induced injury to normal tissue [6,7]. Less commonly, untreated lymph nodes harboring metastatic tumor cells show signs of calcification. These so-called de novo calcifications have been described in several case reports of patients with Hodgkin's lymphoma [8], papillary thyroid carcinoma $[9,10]$, and adenocarcinomas of prostate [11], breast [12], colon [13], ovary [14] and lung [15].

Metastatic nodal calcification can occur as a consequence of dystrophic calcium deposition in areas of necrosis. Dystrophic calcification is the mineralization of soft tissue without a systemic mineral imbalance. Precipitation can occur as a reaction to tissue damage, when unresorbed necrotic material persists for prolonged periods [11]. In our patient imaging suggested that the calcified part of the lymph nodes did not decrease in size and, consequently, did not respond to chemotherapy. However, on pathologic examination no vital tumor cells could be detected in these lymph nodes anymore. To our knowledge, no published data are available on response evaluation in tumor-positive calcified lymph nodes in esophageal cancer.

We hypothesize that calcified lymph nodes cannot decrease in size even in case of adequate destruction of tumor cells by chemotherapy. Their incapacity to shrink should be kept in mind when evaluating response to neoadjuvant or induction chemotherapy. Response measurement should preferably be directed at the change in size of the primary tumor in case calcified lymph nodes are present. 


\begin{tabular}{r|l|l|l} 
Case Reports $/ \mathrm{h}$ & $\begin{array}{l}\text { Case Rep Gastroenterol 2009;3:182-186 } \\
\text { D0I: 10.1159/000226253 }\end{array}$ & Published online: July 3, 2009 & $\begin{array}{l}\text { O 2009 S. Karger AG, Basel } \\
\text { ISSN 1662-0631 } \\
\text { www.karger.com/crg }\end{array}$ \\
\hline
\end{tabular}

Fig. 1. Chemotherapy response evaluation by means of CT scanning showed a clear reduction in wall thickness of the primary tumor, located in the distal esophagus and at the gastroesophageal junction. Pretreatment (a) versus posttreatment (b) (5 months after diagnosis when the patient had completed nine cycles of chemotherapy).
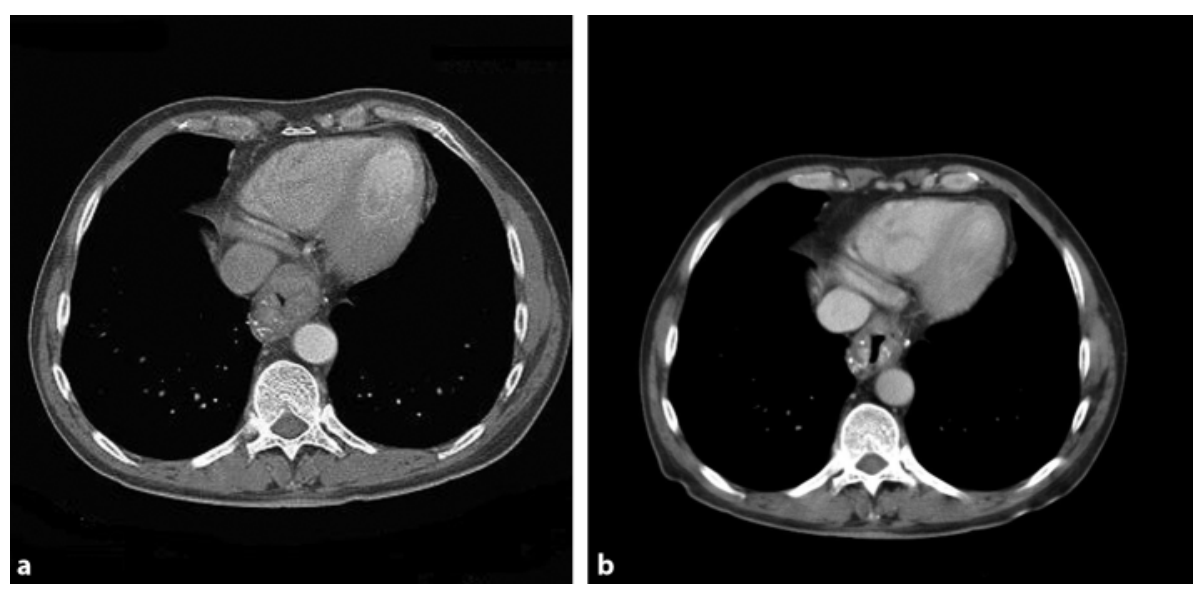

Fig. 2. Chemotherapy response evaluation by means of CT scanning showed the calcified lymph nodes at the celiac trunk that appeared not to have decreased in size. Pretreatment (a) versus posttreatment (b) (5 months after diagnosis when the patient had completed nine cycles of chemotherapy).
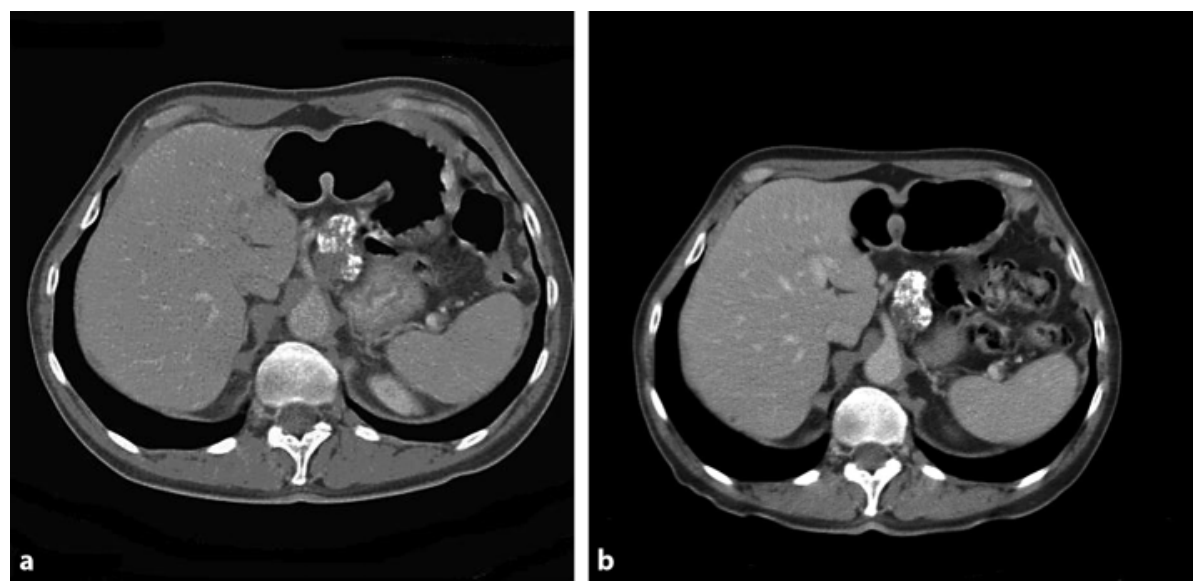


\begin{tabular}{r|l|l|l} 
Case Reports in & $\begin{array}{l}\text { Case Rep Gastroenterol 2009;3:182-186 } \\
\text { D0I: 10.1159/000226253 }\end{array}$ & Published online: July 3, 2009 & $\begin{array}{l}\text { O 2009 S. Karger AG, Basel } \\
\text { ISSN 1662-0631 } \\
\text { www.karger.com/crg }\end{array}$ \\
\hline
\end{tabular}

Fig. 3. On cytological examination after fine-needle biopsy it was shown that the peritruncal calcified lymph nodes harbored tumor cells.

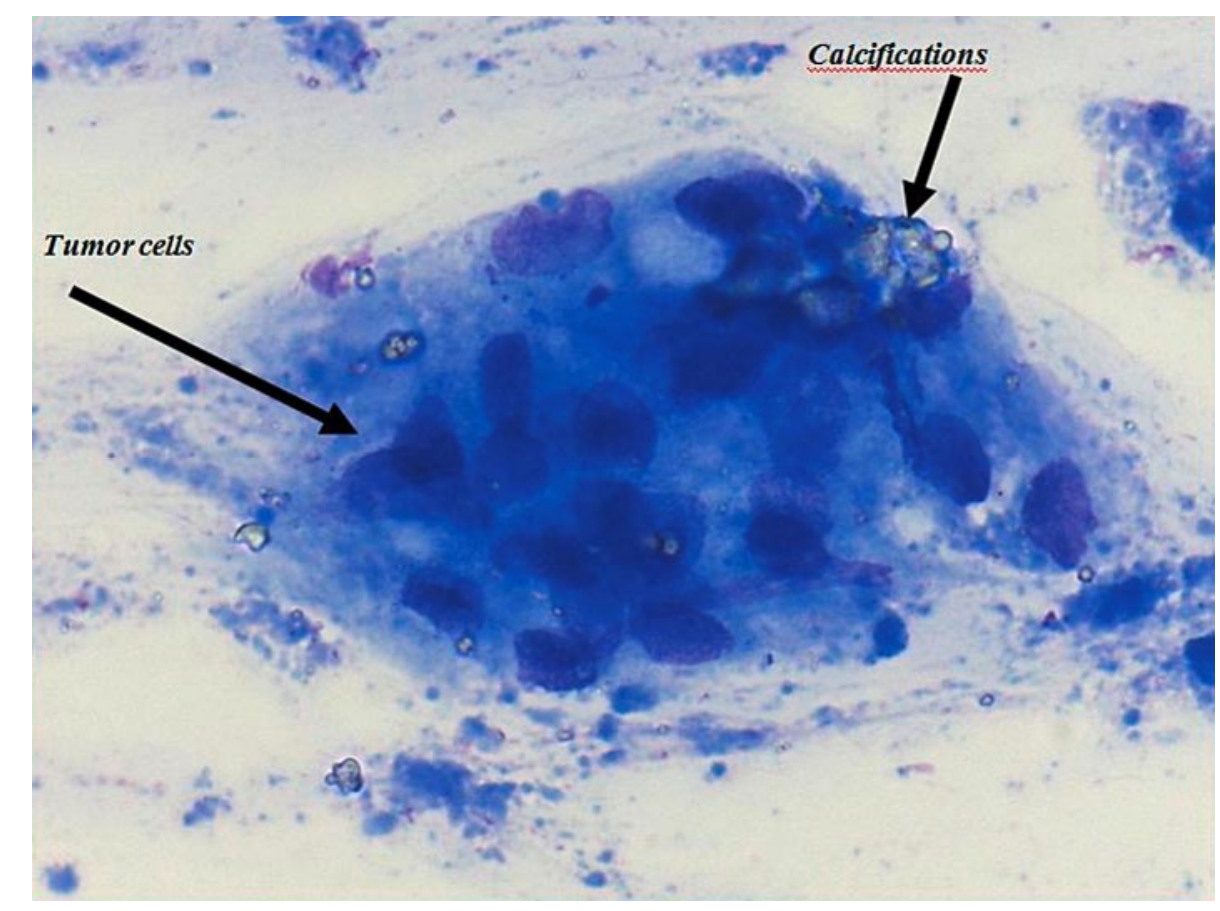




\section{References}

1 Gawne-Cain ML, Hansell DM: The pattern and distribution of calcified mediastinal lymph nodes in sarcoidosis and tuberculosis: a CT study. Clin Radiol 1996;51:263-267.

2 Strijk SP: Lymph node calcification in malignant lymphoma. Presentation of nine cases and a review of the literature. Acta Radiol Diagn (Stockh) 1985;26:427-431.

-3 Ibeas R, Carles J, Miguel A, Gallen M, Busto M: Calcification of lymph node metastases from prostate carcinoma after hormonal treatment: a case report. Prostate 1997;33:147.

-4 Ferretti G, Ranchoup Y, Bost C, Coulomb M: Case report: CT demonstration of supra-diaphragmatic calcified metastatic nodes from ovarian carcinoma. Clin Radiol 1997;52:956-958.

-5 Ghahremani GG, Straus FH 2nd: Calcification of distant lymph node metastases from carcinoma of colon. Radiology 1971;99:65-66.

-6 Bluemke DA, Fishman EK, Kuhlman JE, Zinreich ES: Complications of radiation therapy: CT evaluation. Radiographics 1991;11:581-600.

-7 Mesurolle B, Qanadli SD, Merad M, Mignon F, Baldeyrou P, Tardivon A, Lacombe P, Vanel D: Unusual radiologic findings in the thorax after radiation therapy. Radiographics 2000;20:67-81.

-8 Wycoco D, Raval B: An unusual presentation of mediastinal Hodgkin's lymphoma on computed tomography. J Comput Tomogr 1983;7:187-188.

9 Som PM, Brandwein M, Lidov M, Lawson W, Biller HF: The varied presentations of papillary thyroid carcinoma cervical nodal disease: CT and MR findings. AJNR Am J Neuroradiol 1994;15:1123-1128.

10 Eisenkraft BL, Som PM: The spectrum of benign and malignant etiologies of cervical node calcification. AJR Am J Roentgenol 1999;172:1433-1437.

11 Ghosh P, Santosa AC, Lin GY, Downs TM: De novo calcification of liver and nodal metastases in prostate carcinoma. Prostate Cancer Prostatic Dis 2006;9:448-451.

12 Preda L, Rizzo S, Latronico A, Mastropasqua MG, Bellomi M: Calcified metastatic mediastinal lymph nodes from mucinous breast adenocarcinoma. Eur Radiol 2004;14:1318-1319.

13 Sweeney DJ, Low VH, Robbins PD, Yu SF: Calcified lymph node metastases in adenocarcinoma of the colon. Australas Radiol 1994;38:233-234.

14 Mahon TG, Libshitz HI: Mediastinal metastases of infradiaphragmatic malignancies. Eur J Radiol 1992;15:130-134.

-15 Austin JH, Grimes MM, Carberry D: CT detection of calcified nodal metastases of lung adenocarcinoma. J Comput Assist Tomogr 1988;12:314-316. 